on design, multi-material printing and polymers. Loughborough University will deal with hybrid printing technologies. The University of Liverpool will focus on research into metals, and Newcastle University will specialize in additive manufacturing for biomedical uses.

\section{GOING GLOBAL}

Last September, Nanyang Technological University n Singapore opened the NTU Additive Manufacturing Centre. The centre offers master's degrees in precision engineering, mechanical engineering and manufacturing systems and engineering, all with a specialization in additive manufacturing, as well as a $\mathrm{PhD}$ in mechanical engineering with a topic in additive manufacturing. It is also providing internships to students from around the world.

The creation of the centre has led to postdoc and faculty positions in several disciplines, including

$\sum$ materials science, mechanical engineering, chemical engineering and biomedical engineering, says Chua Chee Kai, who heads it. He says it is too early to predict how many jobs related to $3 \mathrm{D}$ printing there might be in the business world in general, because the technology is in the early stages of adoption. "We

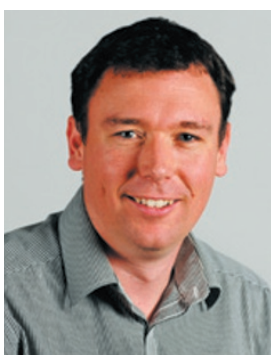

"If you continually develop the materials, then processes will have to change." Christopher Tuck

do, however,

firmly believe that these are high-value jobs that will change the landscape of that particular business or sector," he says. And as the field grows, he predicts, "we will need not just engineers, but also computer experts, mathematicians, software engineers, material scientists, quality experts, systemsolution providers and many more to sustain the economic ecosystem of 3D printing."

Bourell says that even institutions without formal programmes usually have some research going on. "You can pick almost any university and they have some kind of activity these days," he says. "They have at least one person dabbling." He expects the field to evolve and expand rapidly enough over the next 5 to 10 years for there to be considerable demand for people with master's- and PhD-level education. "We're right on the edge of the wave," Bourell says. "Now it's time to jump in."

Neil Savage is a freelance writer in Lowell, Massachusetts.

\section{RESEARCH EFFICIENCY \\ Time wasted}

US scientists are spending $42 \%$ of their time on bureaucratic chores, according to a US National Science Board (NSB) report. The NSB named financial and personnel reporting and over-detailed preliminary grant proposals as common complaints. Arthur Bienenstock, chair of the NSB task force that authored the report, says that the need to submit a detailed budget in the first round of a grant proposal, for example, is 'nonsensical'. The NSB found that an over-regulation culture is overwhelming US scientists, and recommends limiting proposal requirements to those essential for evaluating merit; keeping reporting focused on outcomes; and automating payroll certification.

\section{AWARDS}

\section{Postdoc prizes}

Three science-award recipients based in New York City have pledged US\$3 million of their prize money to set up an endowment to fund awards for postdoctoral researchers. Charles Sawyers of Memorial Sloan Kettering Cancer Center, Cori Bargmann of Rockefeller University and Lewis Cantley of Weill Cornell Medical College last year each won \$3-million 'Breakthrough' prizes. The new Tri-Institutional Breakout Awards for Junior Investigators will offer three to six $\$ 25,000$ awards per year. The endowment founders say they are donating part of their prizes because they believe that postdocs will benefit more from the support. "For me, a prize at that stage of my career would have been really helpful," says Bargmann, who adds that postdocs do much of the most creative work in science. Inaugural winners will be announced by the end of the year.

\section{MULTIPLE DISCIPLINES}

\section{Converging futures}

Exciting future research opportunities will arise where disciplines converge but government funding and academic structures are ill prepared to take advantage of them, says a report from the US National Research Council. Report committee chairman Joseph DeSimone says that this convergence will require scientists to understand the language of multiple disciplines and sectors, and calls $3 \mathrm{D}$ printing (see page 521) a 'wonderful example', as it depends on so many different disciplines. 